\title{
Safety study of cast-in-situ support for double track railway on wide channel beam bridge
}

\author{
Zhenxuan Yu' ${ }^{1}$, Junshun Liang ${ }^{2}$, Shuo Jiang ${ }^{3}$, Shixin $\mathrm{Li}^{4}$, Chao Zou \\ ${ }^{1,2,4,5}$ Guangdong University of Technology, Guangzhou, China \\ ${ }^{3}$ China Railway Guangzhou Group Co., Ltd, Guangzhou, China \\ ${ }^{5}$ Corresponding author \\ E-mail: 13117003065@mail2.gdut.edu.cn, 2792023176@qq.com, ${ }^{3}$ tou1479@foxmail.com, \\ 4980807223@qq.com,55331993@qq.com
}

Received 19 September 2019; accepted 28 September 2019 DOI https://doi.org/10.21595/vp.2019.21041

Check for updates

Copyright (C) 2019 Zhenxuan Yu, et al. This is an open access article distributed under the Creative Commons Attribution License, which permits unrestricted use, distribution, and reproduction in any medium, provided the original work is properly cited.

\begin{abstract}
Prestress concrete channel beam bridge is a new structure suitable for railway bridges. Due to its advantages under stress, construction and economy, channel beam has been widely used and developed rapidly in engineering construction. However, the concrete track bed plate of channel beam bridge has the characteristics of large transverse width and weight, the stress of inclined wall box girder, complicated construction process, difficult control of concrete crack, and high construction technical difficulty. Therefore, it is necessary to study the wide channel beam bridge. This paper carries out safety checking calculation on the support structure of Bailey beams of channel beam bridge. The results showed that the supporting structure can be considered to be safe. The relevant structural safety design can provide reference to similar projects.
\end{abstract}

Keywords: railway engineering, bridge, bailey beams.

\section{Introduction}

Prestress concrete channel beam bridge is a new structure suitable for highway bridges, railway bridges and urban rail transit. Compare with the conventional t-beam bridge and box girder bridge, the channel beam can significantly reduce the height of the superstructure, increase the clearance under the bridge, reduce the height of the embankment, block the traffic noise and prevent the overturning of vehicles. It also has the characteristics of beautiful shape, convenient maintenance and good anti-seismic performance [1]. Due to its advantages under stress, construction and economy, channel beam has been widely used and developed rapidly in engineering construction.

According to the layout of track line, the channel beam bridge can be divided into single channel beam bridge and double channel beam bridge. Due to the deviation between the center line of the line and the central axis of the bridge deck, the structure biased load is obvious when the train is running on one side, and the influence of torque on the main beams on both sides cannot be ignored [2]. In addition, according to the main beam web form, channel beam can be divided into two categories: straight wall type and inclined wall type. The main girder of the straight wall type channel beam bridge adopts vertical web, and the web of the main girder of the inclined wall type channel beam bridge is inclined outwards [3]. By tilting the upper flange to the outside, the main beam spacing of slotted beam of inclined wall type is smaller than that of straight wall slotted beam, which reduces the transverse span of track bed plate [4]. Therefore, slotted beam of inclined wall type has relatively higher utilization rate of section space. Channel beam has become one of the most competitive structural forms in modern urban rail transit viaduct.

However, the concrete track bed plate of channel beam bridge has the characteristics of large transverse width and weight, the stress of inclined wall box girder, complicated construction process, difficult control of concrete crack, and high construction technical difficulty [5]. Especially in the combination of box girder and girder bed plate, the composite effect of bending, shear and torsion is obvious, and the combination of bed plate and girder web is easy to crack. Therefore, it is necessary to study the wide channel beam bridge.

Due to the $48 \mathrm{~m}$ channel beam bridge is first to build for double track railway, it is important 
to evaluate the safety performance of the bridge. In this paper, the safety analysis of the support structure is carried out based on the finite element model, and the conclusion can provide reference for similar engineering applications.

\section{Bridge profile}

The channel beam bridge has the top width of $15.3 \mathrm{~m}$, and the bottom width of $13.2 \mathrm{~m}$. Standard section beam height $3.15 \mathrm{~m}$. The minimum thickness of track bed plate is $70 \mathrm{~cm}$, and the fulcrum is thickened to $130 \mathrm{~cm}$. The side girder adopts inclined wall-type box section. The roof of box girder section is $1.95 \mathrm{~m}$ wide and $55 \mathrm{~cm}$ thick. Web thickness $32-45 \mathrm{~cm}$. The longitudinal, transverse and vertical prestressing forces are set in the whole bridge, among which the longitudinal and transverse prestressing forces are made of low-relaxation steel strand with tensile strength of $1860 \mathrm{MPa}$, with a total of 35 beams in the whole bridge. The vertical prestress adopts PSB830 finished rolled steel bar with diameter of $25 \mathrm{~mm}, 240$ in total. The bridge is cast-in-place construction by bracket, the cross sectional drawing is shown in Fig. 1.

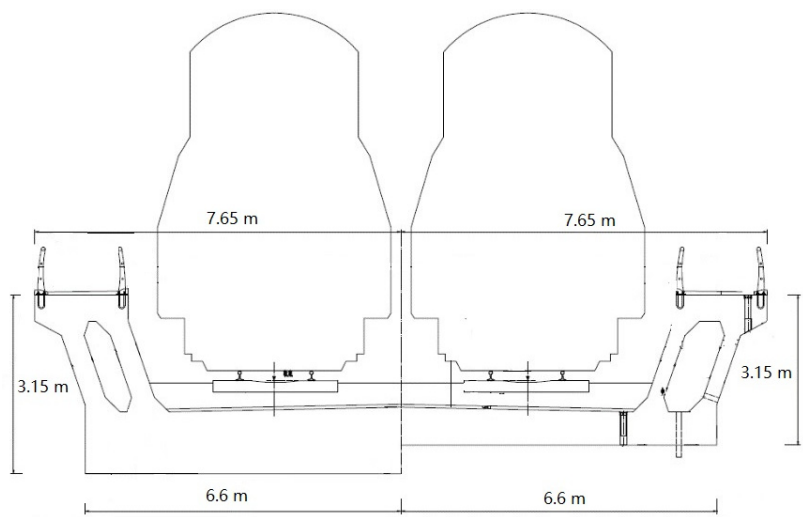

Fig. 1. Cross sectional drawing of bridge

The support system of channel beam is composed of column, transverse distribution beam, longitudinal beam, square wood, and bamboo rubber plate bottom mould system, etc., as shown in Fig. 2. Beam support using 6 row of five columns, a total of 30 posts and $508 \times 8 \mathrm{~mm}$ steel pipe with maximum length $10 \mathrm{~m}$, which welding on caps and bar based on the embedded parts, respectively. The cross-bridge spacing is $2.0+2 \times 3.15+2.0 \mathrm{~m}$, and the consequent-bridge spacing is $8.205+3 \times 9.0+8.205 \mathrm{~m}$. The spiral pipe is decorated with two beams. Bailey beams are arranged on the beam with spacing of $120+5 \times 45+5 \times 120+5 \times 45+120 \mathrm{~cm}$. I14 distribution beams with a spacing of $75 \mathrm{~cm}$ were arranged on the Bailey beam, and $100 \times 100 \mathrm{~mm}$ square wood was placed on the beam. Solid parts under the web were spaced $0.25 \mathrm{~m}$, hollow parts $0.3 \mathrm{~m}$, and groove bottom plates $0.45 \mathrm{~m}$. The bottom mold is $18 \mathrm{~mm}$ bamboo rubber plate for the face.

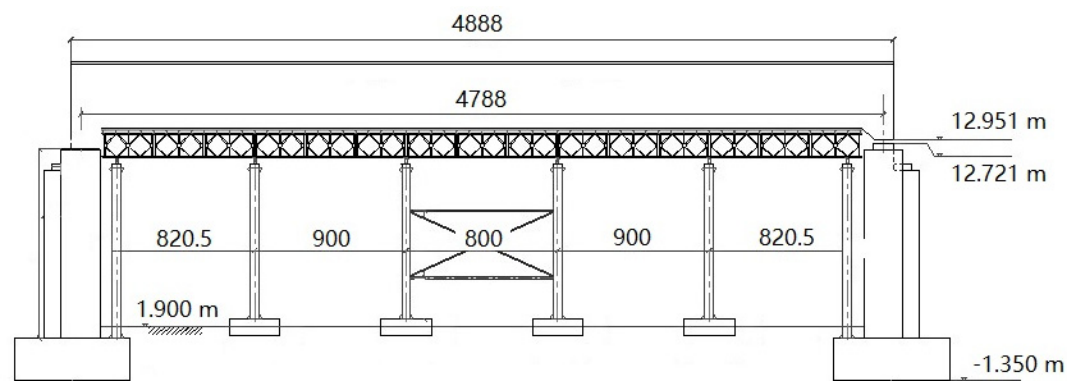

Fig. 2. Support system for bridge (Unit: $\mathrm{mm}$ ) 


\section{Load and material parameters}

According to the actual stress condition of the support, its load value is as follows:

(1) Weight of the structure consists of the weight of steel tube, Bailey beam, I-beam and other structures, which can be directly calculated according to the bulk weight of the material in Midas Civil.

(2) Wet weight load of the main beam: the density of reinforced concrete is $26 \mathrm{kN} / \mathrm{m}^{3}$, according to the actual concrete pouring height on the formwork, and the load distribution of wet weight of concrete is calculated as shown in Fig. 3.

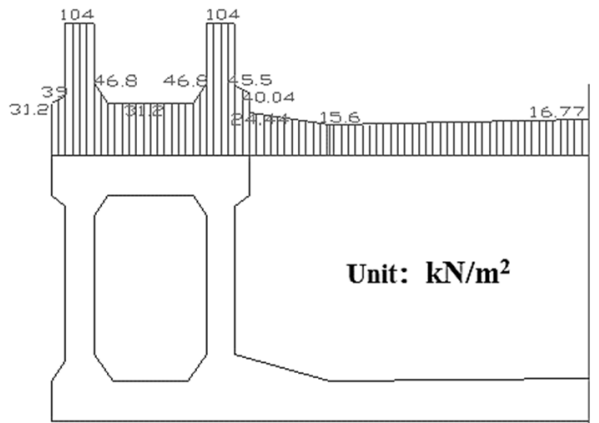

Fig. 3. Wet weight load of the main beam

(3) Main beam formwork and support load is calculated according to uniformly distributed load, which is $2 \mathrm{kN} / \mathrm{m}^{2}$.

(4) Construction personnel and equipment load is $2 \mathrm{kN} / \mathrm{m}^{2}$.

(5) Load generated by vibrating concrete is $4 \mathrm{kN} / \mathrm{m}^{2}$.

(6) Concrete excess irrigation coefficient is 1.05 .

Table 1 gives the mechanical properties parameters of the materials required for calculation.

Table 1. Physical and mechanical properties of the materials

\begin{tabular}{|c|c|c|c|c|}
\hline \multicolumn{2}{|c|}{ Materials } & $\begin{array}{c}\text { 16Mn Low alloy high strength } \\
\text { structural steel }\end{array}$ & $\begin{array}{c}\text { Q235 } \\
\text { steel }\end{array}$ & Wood \\
\hline \multicolumn{2}{|c|}{ Modulus of elasticity / MPa } & $2.1 \times 10^{5}$ & $2.06 \times 10^{5}$ & $9 \times 10^{3}$ \\
\hline \multirow{2}{*}{ Allowable stress / MPa } & $\begin{array}{c}\text { Pull, press, } \\
\text { bend }\end{array}$ & 210 & 140 & 12 \\
\cline { 2 - 5 } & Shear & 120 & 85 & 1.9 \\
\hline $\begin{array}{c}\text { Strength design value / } \\
\text { MPa }\end{array}$ & $\begin{array}{c}\text { Pull, press, } \\
\text { bend }\end{array}$ & 310 & 215 & - \\
\hline
\end{tabular}

Midas Civil was used to establish the overall finite element model of the support system. The overall model has 7233 nodes and 12,590 elements, including 10310 beam elements and 2880 plate elements. The overall finite element model is shown in Fig. 4.

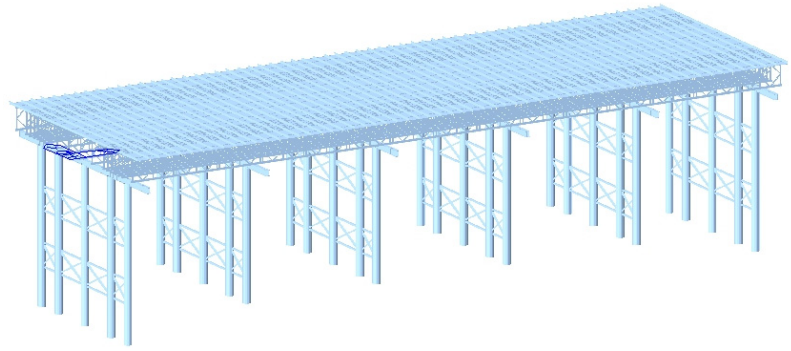

Fig. 4. Finite element model 


\section{Results}

Fig. 5 shows the calculation results of the overall bending moment of support system. It can be seen that the maximum bending moment of the overall structure occurs on the double split I-beam supported by the second row from the outside to the inside, and the maximum bending moment is $229.3 \mathrm{kN} \cdot \mathrm{m}$.
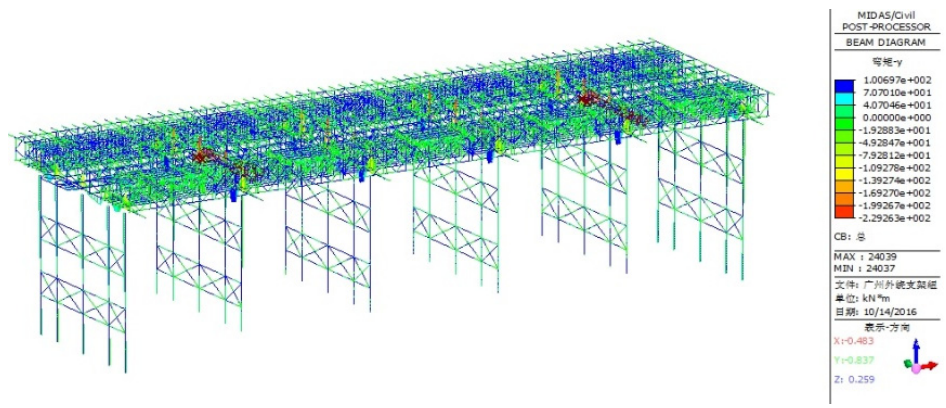

Fig. 5. Overall bending moment

Figs. 6 and 7 show the combined stress and shear stress distribution of the whole structure, respectively. The maximum combined stress of the overall structure is $200.3 \mathrm{MPa}$, which occurs at the lower chord of the most lateral column corresponding to the innermost Bailey beam under the big web. The maximum combined stress is less than the allowable stress of $16 \mathrm{Mn}$ of the Bailey beam, which meets the strength requirements. The maximum shear stress of the overall structure is $84.1 \mathrm{MPa}$, which occurs on the double-spined I-beam on the second row of support from the outside inside. Its value is less than the allowable shear stress of double-spined I-steel Q235, and the shear strength meets the requirements.
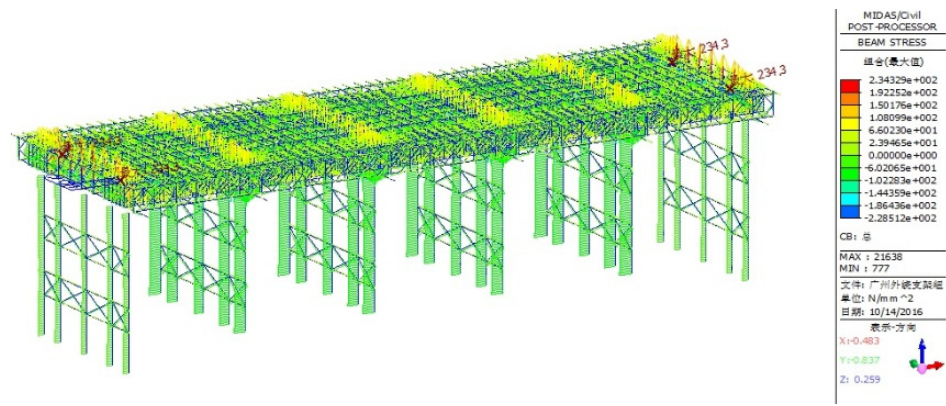

Fig. 6. Combined stress of the overall structure
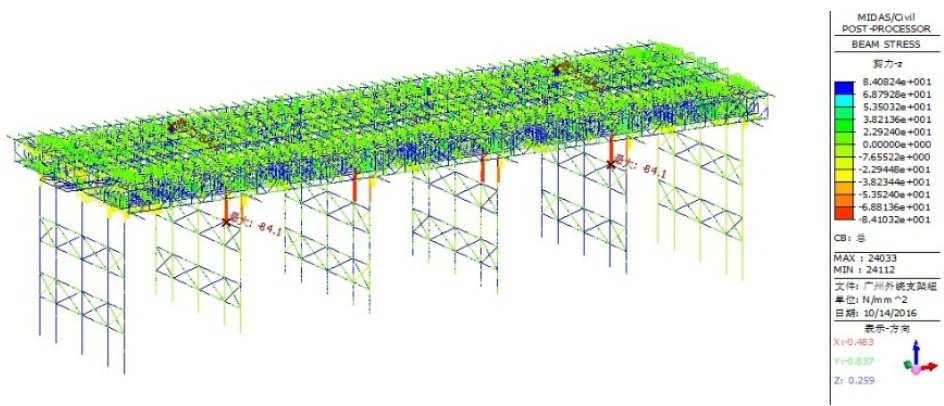

Fig. 7. Shear stress of the overall structure

Fig. 8 shows the overall deformation diagram of the structure. The maximum vertical 
deformation is $8.14 \mathrm{~mm}$ downward, which occurs near the middle position of the side span. The maximum down warping value is less than the deformation limit $L / 400=8205 / 400=20.5 \mathrm{~mm}$, which meets the requirements of stiffness.

The calculated reaction force results of support system are shown in Fig. 9. The maximum support reaction force is $986.7 \mathrm{kN}$, which occurs on the second row of the outermost column.
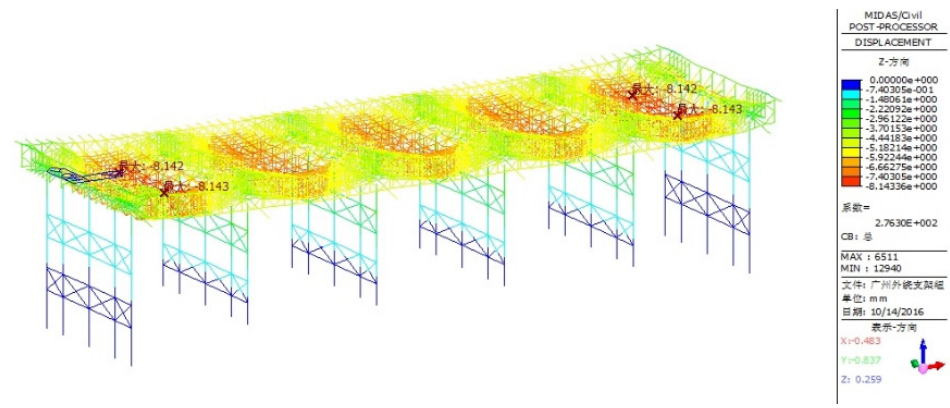

Fig. 8. Deformation of the overall structure

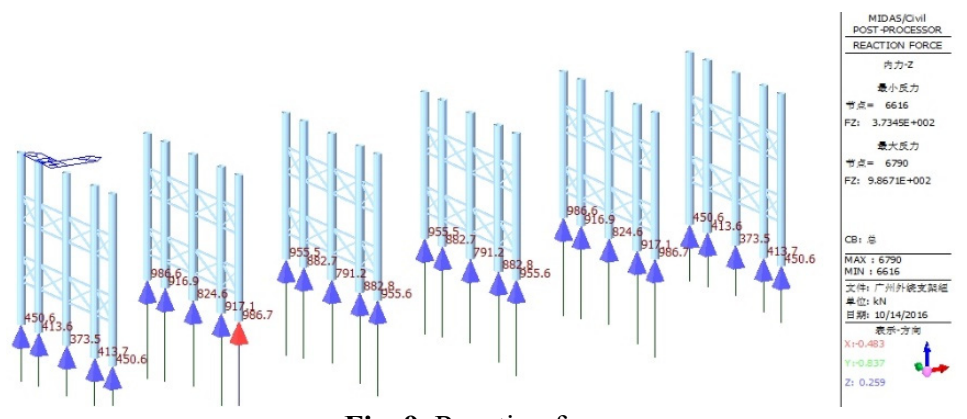

Fig. 9. Reaction force

\section{Conclusions}

In order to ensure the safety of the support structure of a $48 \mathrm{~m}$ channel beam bridge, this paper carries out safety checking calculation on the support structure of Bailey beams of channel beam bridge. The software of Midas Civil was used to establish the finite element model of support system for bridge.

The maximum bending moment, the maximum combined stress, the maximum shear stress, and the overall deformation of the overall structure are calculated based on finite element model, and all of above are meet the requirement of safe, and the supporting structure can be considered to be safety. The relevant structural safety design can provide reference for similar projects.

\section{References}

[1] Xia H., Zhang N. Dynamic analysis of railway bridge under high-speed trains. Computers and Structures, Vol. 83, 2005, p. 1891-1901.

[2] Teng J. G., Yao J., Zhao Y. Distortional buckling of channel beam-columns. Thin-Walled Structures, Vol. 41, 2003, p. 595-617.

[3] Razzaq Z., Prabhakaran R., Sirjani M. M. Load and resistance factor design (LRFD) approach for reinforced-plastic channel beam buckling. Composites Part B: Engineering, Vol. 27, 1996, p. 361-369.

[4] Anapayan T., Mahendran M., Mahaarachchi D. Lateral distortional buckling tests of a new hollow flange channel beam. Thin-Walled Structures, Vol. 49, 2011, p. 13-25.

[5] Torabian S., Zheng B., Schafer B. W. Experimental response of cold-formed steel lipped channel beam-columns. Thin-Walled Structures, Vol. 89, 2015, p. 152-168. 